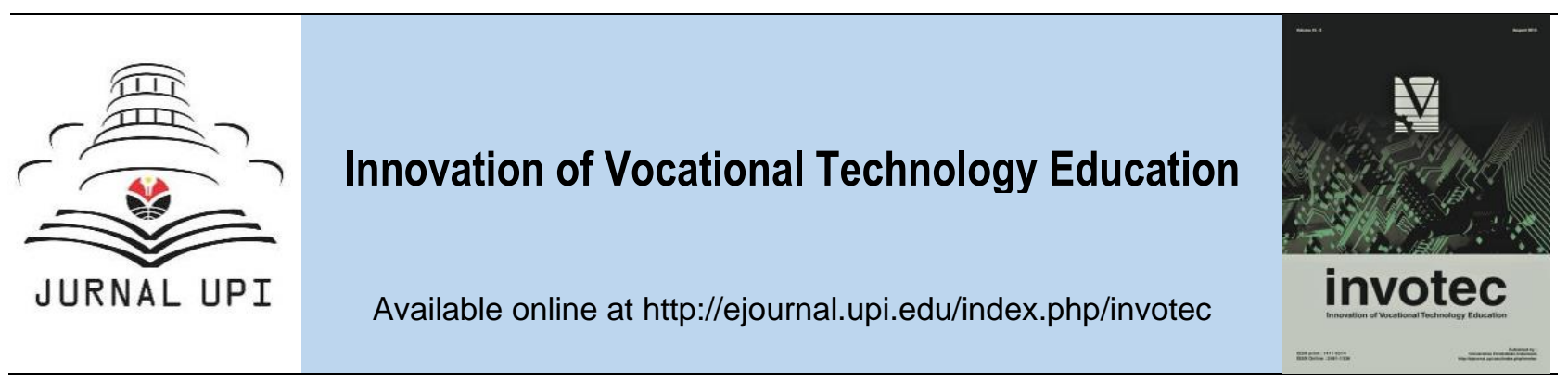

\title{
Student Response - Based Learning: A Strategy for Improving Student Participation in Learning
}

\author{
Karpin and Ai Mahmudatussa'adah \\ Culinary Education Study Program, Universitas Pendidikan Indonesia, Bandung, Indonesia
}

\section{ARTICLE INFO}

Article history:

Received: 28 October 2019

Received in revised form: 13 December 2019

Accepted: 21 January 2020

Available online: 29 February 2020

Keywords:

student response based

learning

Authors email:

karpin@upi.edu

aims@upi.edu

\begin{abstract}
In the context of 21 st century learning, to achieve meaningful learning processes, one of the important elements is interaction. Student response - based learning can be used to actively involve students in the learning process. The study focused on stages of the learning process based on student responses and student responses to the learning. Formulation of the research problem is following: (1) how are the stages of the learning process based on student responses to increasing student participation in learning ?; (2) how is the student response to student response based learning? The research objectives are: (1) increasing the active participation of students in learning through conditioning the learning environment; and (2) describing the steps of the student response-based learning process. The research conducted is a research development. Conclusion of the results of the study: first, the stages of the student response-based learning process (learning model syntax) are (a) uploading teaching materials; (b) Question \& Individual Vote; (c) Peer Discussion; (d) Second Vote; (e) Wholeclass Discussion. These learning steps can increase student participation in learning. Second, students generally give positive responses to student response based learning. A positive response is given to the factor of the variable (a) explanation; (b) facilitation; (c) value; (d) positivity; (e) distraction; and (f) participation.
\end{abstract}

\section{Introduction}

It is believed that interaction is one of the keys in having meaningful learning process, particularly in the context of 21 st century learning. Research results show that increasing interaction in the classroom can lead to better and more interesting learning processes (Beltran, 2018). When being actively involved in learning, participants learn to be more motivated to learn, more attentive, more participatory, and more likely to communicate and exchange ideas with the teacher and between learning participants.

The constructivist learning theory is one of the theories that underlies and reinforces the significance of learning. This theory shows that knowledge is not final and complete. Thus, 
individuals must actively build it through interactions with the physical and social environment. To support it, active learning is a methodology designed to support constructivism through student involvement in the learning process, which enables students to make analyzes, syntheses, and evaluations, thereby developing thinking and reasoning skills (Caceffo \& Azevedo, 2014).

Active learning seems to have become the main choice in current educational practices. In Indonesia, this active learning movement has become increasingly prominent along with efforts to reform national education. This change movement continues until now, teachers and lecturers are continuously encouraged to be able to apply the concept of active learning in every learning practice. Some circles argue that the core of this educational reform lies precisely in the paradigm shift in learning from the passive learning model to the active learning model.

The most important interactive effect in class is that it will affect the learning outcomes of participants in learning, such as attitudes, knowledge and skills. Integration of technology components that are unavoidably intertwined in the lives of learning participants. Technology can be used in learning more efficiently and effectively and to facilitate participant learning in the learning process.

Proliferation of mobile devices is often considered negative, especially in terms of potential interference. The tendency towards different functionalities of types of cellular devices and the potential to cause various ethical problems (Traxler, 2010) is a reason to prevent or even prohibit cellular devices from being activated during lectures (Brenner, 2015). Lecturers and teachers have reasonable concerns about the use of mobile devices, especially cellular devices have the potential to distract participants from the learning activities of lectures. However, the level of proliferation, impracticality that might lead to rejection of the use of the wrong, must be addressed with the use of mobile devices in learning activities (Balakrishnan \& Lay, 2013). Controlling the use of mobile devices with utilization at various stages of learning is one way to minimize the temptation to distractions.

Internet-based learning and mobile devices are considered useful since they can improve academic achievement (Kay \& LeSage, 2009), provide immediate feedback about participants' understanding of learning about lecture material (Keough, 2012), and have higher levels of engagement and satisfaction of learning (Hedgcock \& Rouwenhorst, 2014). Another benefit is increasing the participation of learning participants so that learning becomes centered on learning participants (Caldwell, 2007). The main concerns related to insternet-based learning solutions and mobile devices are the strength and capacity of wi-fi in the lecture hall and the willingness of students to use their personal devices.

All technology used to support learning is based on pedagogics that encourage the selection of tools and ways of use (Beetham \& Sharpe, 2013). In internet-based learning and mobile devices, lecturers need to understand and be able to articulate the goals prepared appropriately, because wasted time and questionable relevance will reduce the commitment of learning participants to participate (Nielsen, Hansen, \& Stav, 2013). 
Based on the description above the authors conducted research on increasing student participation in learning through student response based learning. The research uses the WhatsApp application that is installed on the cellphones of every student participating in the lecture, Google form is a form of free facilities provided by Google, and Wi-Fi can be accessed in the lecture hall. The research conducted is expected to increase student involvement in learning, interaction, or communication that is not possible to achieve using traditional approaches.

Research is focused on the stages of the learning process based on student responses and the impact of learning. The research problem is formulated in the following questions: (1) how are the stages of the learning process based on student responses to increase student participation in learning ?, and (2) how are students' responses to student response based learning?

The research objectives are (1) increasing the active participation of students in learning through efforts to condition the learning environment, (2) describing the steps of the student response-based learning process.

The urgency of research is (1) active learning is a solution to increase student participation in learning, (2) learning innovation is an effort that must be carried out continuously to increase student potential that is the purpose of lectures, (3) student response based learning theoretically can increase participation students who have an impact on increasing mastery of potential demands.

\section{Literature Review}

According to Mahon (2012), Classroom Response System (CRS) is defined as a technology that allows teachers to ask questions or problems in class, participants learn to answer through several types of devices and the teacher can immediately find out individual scores and summarizes the participants' answers. CRS is often referred to in various terms such as Student Response Systems, Audience Response Systems, Personal Response Systems and clickers (Martyn, 2007). The main idea of CRS is that the teacher asks questions and students answer questions. This idea is actually not new. Interactive question and answer has been used by teachers since the time of Socrates. The teacher asks questions and students raise their hands before answering then the teacher points and invites students to answer. But response systems like this don't work well in large classes. Many students are reluctant to talk and engage in learning activities (Caldwell, 2007).

Improvement of mobile device technology currently provides greater opportunities for teachers to use CRS more effectively in learning activities. CRS increases opportunities for students to participate. Teachers and students can benefit greatly from the advantages of CRS. On the other hand, CRS has several potential problems. The use of CRS in learning is still quite new for most teachers. In addition, compiling quality questions and ensuring that the questions raised are aligned with the learning objectives are the key to effective use of CRS in the classroom. Another problem that might occur in using CRS is an unstable or disconnected internet connection (Lander \& Stoeckel, 2012). 
The Student Response System (SRS) can be described as an electronic voting system that presents students with multiple choice questions, which they will answer with a mobile device. The benefits of using such a system in lectures can increase student motivation and involvement, clarification of mistakes more easily (Rice \& Bunz, 2006), promotion of active learning (Boyle \& Nicol 2003) and increase student performance (Rao \& DiCarlo, 2000), including better conceptual understanding (Crouch \& Mazur, 2001).

The teacher can use a number of strategies when implementing CRS in the classroom. These strategies are: (a) immediate feedback, (b) classroom monitoring, (c) audience-paced instruction, (d) peer instruction, (e) equal participation, (f) game-based learning, and (g) formative assessment.

Direct feedback on student responses facilitates retention and provides opportunities for students to improve their choice of answers that were initially wrong (Turning Technologies, 2010). The teacher prepares various types of questions, such as true-false and multiple-choice questions, and during the presentation asks those questions to students. The teacher accepts student answers and can present the results of student answers simultaneously and immediately. By participating in answering the questions raised, students are more involved in learning.

In large classes, teachers often have difficulty monitoring student participation (Lander \& Stoeckel, 2012). By using CRS software, teachers can monitor student participation with much easier effort (Caldwell, 2007; Carnegie University Mellon, 2007).

The ability to modify learning strategies and teaching speed based on student understanding is a core concept of student response based learning (Carnegie Mellon University, 2007). But without a way to measure student understanding, the teacher will not realize the need to modify learning. One of the main objectives of using CRS is to adjust the pace of learning based on students' level of understanding.

After students answer the questions asked by the teacher in class and check all the answers, they can discuss the results of their answers and reach agreement on the correct answers (Mahon, 2012). This is a peer instruction process (Carnegie Mellon University, 2007; Turning Technologies, 2010). CRS can also be used as an effective tool for peer learning. The teacher can collect data on students' level of understanding of the topic being studied and immediately adjust their learning strategies.

There is a tendency for learning to be dominated by some students or dominated by teachers, which in turn causes uneven student participation in learning activities (Lander \& Stoeckel, 2012). CRS provides a solution to the problem of uneven participation in the classroom by providing equal opportunities for all students to participate in answering questions. By using CRS, teachers can provide equal opportunities for all students to engage in learning activities in class.

CRS supports game-based learning principles such as competitive practice at the individual and team level (Martyn, 2007). For example, the teacher can form two separate student teams and ask the two teams to compete in a set of quizzes. A game-based approach to lectures can increase student motivation and encourage more active participation. 
CRS can be a useful tool for formative assessment, through the teacher's ability to examine students' level of knowledge and understanding of concepts in real-time. In addition, learning that is adjusted to the speed of student learning and peer learning, CRS as a formative assessment tool can be used to modify teaching steps and strategies.

The constructivist learning theory shows that knowledge is not final and complete. Thus, individuals must actively build it through interactions with the physical and social environment. To support it, active learning is a methodology designed to support constructivism through student involvement in the learning process, which enables students to make analyzes, syntheses, and evaluations, thereby developing thinking and reasoning skills (Caceffo \& Azevedo, 2014).

Empirical research that investigates the effectiveness of the strategies used in activities in the classroom, provides advice on how to introduce various types of instructions and minimize negative reactions. Three ways to reduce student resistance. First, learning activities begin with an explanation of the learning objectives, the learning process to be carried out and the difficulties that may arise. Second, ask for feedback from students as a material for improvement and provide assistance to students in achieving learning objectives. Third, design appropriate and challenging learning activities.

Characteristics of student responses to types of instruction are conceptualized into three forms: cognitive involvement (psychological investment in classroom activities), affective emotional involvement (social and emotional connections to the classroom), and behavioral engagement (students' behavior in the classroom) (Skinner \& Pitzer, 2012). Fourth, the concept of evaluation was added because students placed the instructor's rating at the end of the semester. The four subscales used include: (1) value- the extent to which students see activity as valuable (cognitive); (2) positivity - how students' positive or negative feelings about learning activities (affective-emotional); (3) participation - the extent to which students do or do not participate or show resistance (behavior); and (4) evaluation - the way students assess instructors or courses at the end of the semester.

\section{Research Methods}

The research was conducted in the Culinary Education Study Program, Home Economic Departement, Faculty of Technological and Vocational Education, Universitas Pendidikan Indonesia, Indonesia, located at JI. Dr. Setiabudhi No. 207 Bandung. The study was conducted for eight months. Field research activities were carried out from June 2019 to November 2019. The research conducted was a research development. The research used WhatsApp to present lecture material, Google forms to present questionnaires and tests, as well as student mobile devices to fill in lifts and answer tests.

Following is the design of student response based learning research:

- Uploading teaching materials 
Teaching material is uploaded via WhatsApp Social Media. Teaching material is sent to the class chair who is then sent to their class's WhatsApp group. The uploaded teaching material is the following week's lecture material, so students have the opportunity to study course material a few days before lecturing.

- Question and individual vote

At the beginning of the lecture the lecturer asked questions that had been prepared in the Google form. Students are given time to think about answers to questions posed individually and answer individually using a mobile device.

- Peer discussion

Before the lecturer shows the distribution of individual answers, students are given the opportunity to discuss questions in pairs or in small groups. The lecturer goes around the class to look at students' discussions.

- Second vote

Students are asked to answer the same questions individually based on the results of their discussion using a mobile device.

- Whole-class discussion

The lecturer shows the student answers using a projector. Impressions distribution of student answers containing the first answer and the second answer to the same question submitted via the google form. After students examine their answers, a follow-up discussion is followed. The follow-up discussion is a class discussion guided by the lecturer to better understand the reasons for the right and wrong answers. Through class discussion it is expected that all students master lecture material completely.

- Repeat step 1 to step 5 for several lectures

- Filling out the questionnaire

Questionnaire filling aims to see student responses to the learning that has been done, namely student response based learning.

The research subject is a learning process based on student responses. The study was conducted at the Culinary Education Study Program Indonesia University of Education. In the study used two instruments. First, a test to measure students' mastery of lecture material. Second, a questionnaire to measure student responses to learning conducted in research.

\section{Results and Discussion}

It was agreed that that lecture material would be shared via WhatsApp. Lecture material is delivered to the class president a few days before the lecture, then distributed to all class members through the class WhatsApp group. There are significant benefits from using WhatApp to deliver lecture material; first, recovery materials can directly reach the "hands" of students; second, shortly after the material being sent, students can study teaching material and; third, there is an effort to 
make it a habit for students to use cell phones for useful things. Google forms are used to present tests and questionnaires. Students use cellular devices to answer tests and fill out questionnaires.

\subsection{Test results and discussion data}

Test result data is research data about students' mastery of lecture material. The lecture uses the design of student response-based learning steps. There are two types of test result data, namely individual vote data and second vote data.

Individual vote data is data about students' answers to questions asked at the beginning of lectures. Lecturers submit questions via Google Form, students access and answer questions using a mobile phone. Students answer questions individually based on the results of understanding the lecture material that they have received a few days before lecturing. Second vote data is data about students' answers to the same questions based on the results of the peer discussion. Students answer questions individually based on the results of peer discussion in class while lectures take place.

This section presents two pairs of individual vote and second vote data. First, a pair of individual vote and second vote data from the results of the first lecture, the first time the design of student response-based learning steps is used in lectures. Second, a pair of individual vote and second vote data from the results of the last lecture, when the design of student response-based learning steps was used at the end of the study.

Student answer score data in the first vote individual lectures on questions raised through the Google form, the average score of student answers is 6.58; a median of 6.0; range 3-10 (the smallest score is 3 and the biggest score is 10) of the ideal total score of 13. Student answer score data in the second vote of the first lecture on questions submitted through Google Form, the average score of student answers is 12.19; a median of 13.0; range 7-13 (smallest score of 7 and biggest score of 13) of an ideal total score of 13.

In the first lecture, the design of student response - based learning steps was first applied. For lecturers and students the learning model is new. Nevertheless there has been an increase in the score of student answers from individual votes to the second vote. This shows that the peer discussion conducted by students can improve students' understanding of lecture material.

Data score of student answers on individual votes last lecture on questions raised through the Google form, the average score of student answers is 15.68; median 16; range 8-18 (smallest score of 8 and biggest score of 18) of an ideal total score of 18 .

At the end of the study, lecturers and students already had experience from previous lectures about the application of learning measures based on student responses. Students are more motivated to study the recovery material they received before lecturing. Increased student motivation can be explained by the results of individual votes. The results of individual votes show student mastery of course material that is studied independently. The average score of student answers is 15.68. The average score is greater than the average ideal score (Mean ideal $=9$ ). Median score of 
student answers 16 . Viewed from the median, $50 \%$ of students get a score of 16.0 or more than the ideal total score of 18 . Although the range of scores is still large (8-18), but the smallest score is close to the average ideal score.

Student answer score data on the second vote of the last lecture on questions raised through the Google form, the average score of student answers was 17.83; a median of 18.0; range 15-18 (the smallest score is 15 and the biggest score is 18) of the ideal total score of 18.

Second vote result data in the last lecture, there is an increase in the score of student answers from individual vote results. The median score of student answers is 18.0 from an ideal total score of 18 . This means that $50 \%$ of students have reached the ideal total score. The narrower range of student answers (15-18). The student answer score can be said to be homogeneous with the smallest score of 15 . Almost all students can answer all the items posed correctly.

Based on test result data, peer discussion is very instrumental in student response based learning. Peer discussion can increase student participation in learning. Increased student participation in learning has a positive impact on the mastery of lecture material. This is indicated by the increasing score of the test results.

\subsection{Questionnaire results data and discussion}

Questionnaire is used to measure student responses to student response based learning. There are two variables of student responses to response-based learning, namely learning strategies and student responses to learning. The learning strategy variable consists of two factors, namely explanation and facilitation. While the student response variable to learning consists of four factors, namely the value factor, positivity factor, distraction factor, and participation factor.

\subsubsection{Learning strategies}

- Explanation factor

Data about students' responses to learning strategies on explanation factors, in general students responding to response-based learning (1) clearly explains what students expect to be done in lecture activities; (2) clearly explains the purpose of lectures; (3) the relationship between lecture material and demands of potential are discussed; and (4) giving lecture feedback.

Student response based learning can be taught by lecturers and can minimize negative reactions. The lectures conducted meet the expectations of students. Immediate feedback can be given during class discussions. Class discussion activities discuss about students' answers to the questions submitted through the Google form. Through class discussions, students gain an understanding of lecture material in accordance with competency demands.

- Facilitation factor

Data about student responses to learning strategies on facilitation factors, in general students responding to response-based learning (1) can encourage students to play an active role in lectures; (2) provide sufficient time to engage in lecture activities. 
Learning based on student responses, does not provide opportunities for learning trends dominated by some students or dominated by teachers. Learning provides equal opportunities for all students to participate (Equal participation). Student response based learning provides solutions to overcome the problem of uneven student participation. Lecturers provide equal opportunities for students to be involved in lectures.

\subsubsection{Student response to learning}

- Value factor

Data about students' responses to learning based on student responses to the value factor, in general students responding to response-based learning (1) students feel the efforts made to participate in beneficial lecture activities; (2) students feel that lecturers have an important role in lectures; (3) students see the value (value) in lecturing activities; (4) students find the time spent in lecturing activities useful.

Student response based learning has involved several cognitive elements that are influenced by students' thoughts, beliefs and expectations. Students understand and accept the reasons for attending lectures. Students find the time spent on attending lectures useful. Response-based learning is believed by most students to meet their expectations.

- Positivity factor

Data about student responses to learning based on student responses to positivity factors. Based on the data obtained, in general students respond to response-based learning (1) students respond positively to lecturers; (2) as a whole, the subject is a much needed course; (3) overall, lecturers supporting subjects are very good lecturers; (4) students will recommend the lecturer to other students.

Learning based on student responses, made the lecture participants aware of the importance of the lecture material being studied. Students feel the importance of the presence of lecturers in lectures by giving a positive response to the lecturer. Student response based learning has involved emotional affective as a reaction to what is experienced in lectures. Positive reactions felt by students are no anxiety, feelings of need, no boredom and growing interest in learning.

- Distraction factor

Data about student responses to learning based on student responses to the distraction factor, in general students responding to response-based learning (1) students do not distract their peers during lecture activities; (2) participate in lecture activities; (3) there are students who discuss topics other than the topic being discussed in lectures; (4) there are students who browse the internet, check social media, or do something else, besides doing activities in lectures; (5) students seriously attend lectures.

During the lecture there were students who showed passive resistance, non-verbal resistance by shifting their attention, and doing other course work. The positive response given by students is not to distract the attention of their peers during lecture activities and to seriously attend lectures. 
- Participation factor

Data about student responses to learning based on student responses to participation factors, in general students responding to response-based learning (1) students make a lot of effort to take part in lecture activities; (2) students try their best to do good work; and (3) there are still students who do not play an active role in lectures.

\section{Conclusion}

Referring to the formulation of the problem and the purpose of research on learning based on student responses as a strategy to increase student participation in learning, two conclusions are drawn. First, the stages of the student response-based learning process (learning model syntax) are (a) Uploading teaching materials; (b) Question and individual vote; (c) Peer discussion; (d) Second vote; (e) Whole-class discussion. These learning steps can increase student participation in learning. Second, students generally give positive responses to student response based learning. A positive response is given to the factor of the variable (a) explanation; (b) facilitation; (c) value; (d) positivity; (e) distraction; and (f) participation.

The research has described the syntax of the student response - based learning model and is equipped with a questionnaire that has construct reliability. Although the syntax of the student response-based learning model that was identified in this study was carried out in a limited scope in the context of learning in the Culinary Education Study Program, Home Economic Departement, Faculty of Technology and vocational, Indonesia University of Education, researchers hope that the learning model is relevant for a broader scope and the context of learning in other fields.

\section{References}

Balakrishnan, V., and Lay, G. C. (2013). Mobile wireless technology and its use in lecture room environment: An observation in Malaysian Institutes of higher learning. International Journal of Information and Education Technology, 3(6), 634.

Beetham, H., and Sharpe, R. (2013). Rethinking pedagogy for a digital age: Designing for 21st century learning. Oxon: Routledge.

Beltran, J. C. (2018). Examining the effects of the Application of a Student Response System in teaching Media and Information Literacy to Senior High School Students. Philippines: Ateneo De Manila University.

Boyle, J. T., and Nicol, D. J. (2003). Using classroom communication systems to support interaction and discussion in large class settings. Association for Learning Technology Journal, 3(11), 43-57.

Brenner, T. (2015). The use of Mobile Devices in the College Classroom. Harvard University: The Derek Bok Center for Teaching and Learning. [Online]. Retrieved from: http://bokcenter.harvard.edu/blog/use-mobile-devices-college-classroom [Accessed on: November 20, 2017]. 
Caceffo, R., and Azevedo, R. (2014). LSQuiz: A Collaborative Classroom Response System to Support Active Learning through Ubiquitous Computing. Presented at International Conference on Cognition and Exploratory Learning in Digital Age (CELDA) 2014. [Online]. Retrieved from: https://www.learntechlib.org/p/158040/ [Accessed on: November 24, 2019].

Caldwell, J. E. (2007). Clickers in the large classroom: Current research and best-practice tips. CBE Life Sciences Education, 6(1), 9-20.

Carnegie Mellon University. (2007). A teaching with technology white paper: Classroom response system. [Online]. Retrieved from: http://www.cmu.edu/teaching/technology/whitepapers/ [Accessed on: August 15, 2016].

Crouch, A. H., and Mazur, E. (2001). Peer instruction: ten years of experience and results. American Journal of Physics, 69(9), 970-977.

Hedgcock, W. H., and Rouwenhorst, R. M. (2014). Clicking their way to success: using student response systems as a tool for feedback. Journal for Advancement of Marketing Education, 22(2), 16-25.

Kay, R. H., and LeSage, A. (2009). Examining the benefits and challenges of using audience response systems: A review of the literature. Computers \& Education, 53(3), 819-827.

Keough, S. M. (2012). Clickers in the Classroom: A Review and a Replication. Journal of Management Education, 36(6), 822-847.

Lander, B., and Stoeckel, S. (2012). Tips \& trends: Classroom response systems. [Online]. Retrieved from: http://acrl.ala.org/IS/wp-content/uploads/2014/05/2012 winter.pdf [Accessed on: August 15, 2016].

Mahon, K. (2012). Using student response systems to improve student outcomes. THE Journal White Papers, 27, 1-13.

Martyn, M. (2007). Clickers in the classroom: An active learning approach. Educause Quarterly, $30(2), 71-74$.

Nielsen, K. L., Hansen, G., and Stav, J. B. (2013). Teaching with student response systems (SRS): lecturer-centric aspects that can negatively affect students' experience of using SRS. Research in Learning Technology, 21, 1-13.

Rao, S. P., and DiCarlo, S. E. (2000). Peer instruction improves performance on quizzes. Advances in Physiology Education, 24, 51-55.

Rice, R. E., and Bunz, U. (2006). Evaluating a wireless course feedback system: the role of demographics, expertise, fluency, competence, and usage. Studies in Media \& Information Literacy Education, 6(3), 1-32.

Skinner, E. A., and Pitzer, J. R. (2012). Developmental dynamics of student engagement, coping, and everyday resilience. In Handbook of research on student engagement (pp. 21-44). Boston, MA: Springer.

Traxler, J. (2010). Students and mobile devices. Alt-j, 18(2), 149-160.

Turning Technologies. (2010). Turning technologies solutions learning theories supported. [Online]. Retrieved from: https://www.turningtechnologies.com/pdf/CorpGov/Pedagogy-CorrelationCharts-Sept10.pdf [Accessed on: August 15, 2016]. 